\title{
CADEIAS REFERENCIAIS E PRODUÇÃO DE SENTIDOS NO JORNALISMO POPULAR
}

\author{
Wagner Alexandre dos Santos COSTA ${ }^{1}$ \\ Vanda Maria Cardozo de MENEZES ${ }^{2}$
}

\begin{abstract}
Resumo: As sucessivas retomadas de um item lexical no texto formam uma cadeia textual/referencial. O estudo da fabricação dessas cadeias pode ser um valioso instrumento para desvelar procedimentos linguístico-discursivos vários em textos noticiosos, como a evolução informacional, a construção de drama/humor, bem como observar a perspectiva pela qual um conteúdo é interpretado pela instância produtora, o jornal. Neste estudo, que se vincula à Linguística textual, desenvolveu-se uma análise qualitativa sobre a progressão referencial de certos itens lexicais referencialmente instáveis, presentes no título de notícias do jornal popular carioca Meia Hora, em conformidade com Mondada (2005), Koch e Elias (2008), Marcuschi (2004), Cavalcante (2011) e Roncarati (2010). Nos procedimentos metodológicos, isolamos as cadeias referenciais das notícias do corpus e estabelecemos as relações entre seus componentes, procurando compreender o processo de estabilização do item-fonte, presente no título. Os resultados demonstram que, no material analisado, o subtítulo é o espaço primeiro para a construção de hipóteses afinadas ao conteúdo global do texto. Observou-se, ainda, que a cadeia referencial perfaz uma trajetória do $(+)$ informal e $(+)$ metafórico/instável ao (+) formal e (+) referencial/estável. Além disso, consideramos ser a categoria título, sobretudo na esfera jornalística, uma unidade também referencial dinâmica, recategorizável, instável e em construção no fio do discurso.
\end{abstract}

Palavras-chave: Cadeias referenciais. Estabilização. Jornalismo popular.

\section{Introdução}

No desenvolvimento de nossa atividade discursiva, de escrita ou fala, de produção ou interpretação, lançamos mão de recursos variados por meio dos quais gerenciamos a

\footnotetext{
${ }^{1}$ UFRRJ - Universidade Federal Rural do Rio de Janeiro - Departamento de Letras e Comunicação. Seropédica - Rio de Janeiro - Brasil. 23890-000 - wagnerasc@bol.com.br

${ }^{2}$ UFF - Universidade Federal Fluminense - Departamento de Letras Clássicas e Vernáculas. Niterói - Rio de Janeiro - Brasil. 24220-900 - vcmenezes@terra.com.br

http://dx.doi.org/10.21165/gel.v13i3.1068
} 
interação, frequentemente construindo cadeias referenciais. Essa atividade pressupõe que façamos constantemente referência a algo, alguém, fatos, eventos, sentimentos e mantenhamos em foco os referentes introduzidos por meio da operação de retomada. Além disso, inclui que desfocalizemos referentes e os deixemos em stand by, para que outros referentes sejam introduzidos no discurso e o processo recomece.

$\mathrm{Na}$ base dessa atividade, relacionam-se dois processos que não se separam rigorosamente: o de referenciação, que corresponde a colocar em cena no texto novas entidades e referentes, e o de progressão referencial, relacionado ao processo de textualidade e continuidade tópica do texto, pois inclui a retomada de referentes já introduzidos ou que servem de base, por meio de alguma associação, para introdução de novos referentes.

Em relação à categoria título, no jornalismo popular, o estilo de linguagem adotado na sua elaboração, em geral, destaca-se por apresentar uma relação peculiar entre a forma e o conteúdo dos enunciados. Alguns títulos podem ser considerados semanticamente desviantes, uma vez que possibilitam ao leitor interpretações que não necessariamente são desenvolvidas no corpo do texto. Tais interpretações são possíveis ao leitor a partir da materialidade do texto por meio de processos referenciais, que incluem operações cognitivas e inferenciais mobilizadas na atividade de leitura.

Uma abordagem dessas ocorrências à luz de processos referenciais de construção de sentidos pode nos mostrar, com base na análise de cadeias referenciais, que a instabilidade atribuída ao título, aqui concebido como uma unidade referencial, resolvese por meio da evolução de certos objetos de discurso nele presentes.

A par disso, neste estudo, pretendemos demonstrar que: a) certos títulos contêm objetos de discurso com base nos quais o leitor pode ativar informações armazenadas em sua memória e atribuir à notícia uma coerência no processo inicial de leitura diferente da atribuída ao final dela e que, portanto, b) a relação entre título e texto será, a priori, instável, uma vez que o leitor deverá confirmar a expectativa de significação para a qual aquele aponta. Ademais, defendemos no texto a tese de que a categoria título, pertencente a um esquema textual, aqui sob foco a notícia jornalística, é uma unidade referencial e, como tal, pode ser também recategorizada.

Para tanto, foram analisadas três notícias extraídas do jornal popular Meia Hora, de corpus organizado entre os anos de 2010 e 2013, sobre as quais realizamos uma análise 
qualitativa com base na constituição de cadeias referenciais envolvidas na instabilidade de certas referências. São elas: Novo cardápio da cadeia: Pão com Ovo e Barbie ganha vida, publicadas em 20/08/2011 e 1\%09/2011, respectivamente.

Dentro dessa perspectiva de abordagem, que é sociocognitiva e interacional, entende-se que a atividade linguística tem como base o processo de interação entre as pessoas, que discursivamente constroem e reconstroem o mundo. Deste modo, privilegiamos, nessa vinculação teórica, considerações de autores como Mondada (2005), Koch e Elias (2008), Marcuschi (2004), Cavalcante (2011) e Roncarati (2010).

\section{Referenciação como atividade dinâmica de (re)construção de sentidos}

Estudos sobre referência não são uma novidade, pois uma concepção de referência atrelada à filosofia da linguagem vem desde a Antiguidade, considerando como unívoca e objetiva a relação entre objetos discursivos e objetos do mundo, entre palavras e coisas.

Conforme demonstra Cavalcante (2011, p. 19), filósofos como Platão e Aristóteles já refletiam sobre linguagem e referência distinguindo conceitos de “expressão", "conteúdo" e "referente". Segundo tal visão, o referente correspondia à "coisa" e a referência constituía a relação entre linguagem e exterioridade. Ou seja, os registros desses primeiros pensamentos diziam que o referente seria o próprio objeto da realidade, designado pelas expressões linguísticas. Assim, a língua representaria perfeita e adequadamente o mundo, que estaria pronto, de tal modo que ela (a língua) refletia o mundo, representava-o fidedignamente, independente dos sujeitos.

Atualmente, entende-se a referência não a partir de uma relação estática, na qual a língua seria um instrumento simplesmente acabado e pronto para representar o mundo com fidelidade. Essa alteração de enfoque é defendida por Marcuschi (2004, p. 263) quando propõe "mudar a forma de contemplar a questão saindo da ideia de relação para a de $a c ̧ a \tilde{o}$ " (grifos do autor), ideia que já se entrevê, também, na citação de Malinowski feita por Benveniste.

Cada enunciação é um ato que serve ao propósito direto de unir o ouvinte ao locutor por algum laço de sentimento, social ou de outro tipo. Uma vez mais, a linguagem nesta função manifesta-se-nos, não como instrumento de reflexão, mas como um modo de ação (MALINOWSKI apud BENVENISTE, 2006, p. 90). 
São, pois, conforme esta visão, muito mais complexas as relações entre língua e mundo, segundo as quais, "os sujeitos constroem, através de práticas discursivas e cognitivas social e culturalmente situadas, versões públicas do mundo.” (MONDADA; DUBOIS, 2003[1995], p. 17). Ou seja, afirma-se que as categorias e os objetos de discurso pelos quais os usuários compreendem o mundo se desenvolvem e se modificam conforme o contexto. Tais objetos não são preexistentes, nem são já dados, convencionais ou fixos.

Mondada (2005, p. 11), ao tratar da questão, propõe que se adote o termo "referenciação" em vez de "referência" e, em decorrência, propõe também a substituição do termo "referente" pelo termo, que melhor atende a tal proposta, "objeto de discurso". Assim diz a autora:

\begin{abstract}
A questão da referência [...] foi historicamente posta como um problema de representação do mundo [...]. A questão da referenciação opera um deslizamento em relação a este primeiro quadro: ela não privilegia a relação entre as palavras e as coisas, mas a relação intersubjetiva e social no seio da qual as versões do mundo são publicamente elaboradas [...].

No interior dessas operações de referenciação, os interlocutores elaboram objetos de discurso, i.e., entidades que não são concebidas como expressões referenciais em relação especular com objetos do mundo ou com sua representação cognitiva, mas entidades que são interativamente e discursivamente produzidas pelos participantes no fio de sua enunciação. [...] Dito de outra forma, o objeto de discurso não remete a uma verbalização de um objeto autônomo e externo às práticas linguageiras; ele não é um referente que teria sido codificado linguisticamente. (MONDADA, 2005, p. 11)
\end{abstract}

A passagem da referência para a referenciação, como explicam Mondada e Dubois (2003), tem como pressuposto não apenas a visão do sujeito como um ser "encarnado" (em oposição a uma concepção abstrata e ideal de sujeito), mas também a de um sujeito que interage sociocognitivamente com o mundo. Deve-se destacar, ainda, segundo as autoras, que

[...] não se pode mais, a partir de agora, considerar nem que a palavra ou categoria adequada é decidida a priori "no mundo", anteriormente à sua enunciação, nem que o locutor é um locutor ideal que está simplesmente tentando buscar a palavra adequada dentro de um estoque lexical. [...] $\mathrm{O}$ ato de enunciação representa o contexto e as versões intersubjetivas do mundo. (MONDADA; DUBOIS, 2003, p. 17) 
Posto isso, concebendo o mundo como um fluxo constante de estímulos, os objetos são construídos através dos processos cognitivos dos sujeitos, a partir de categorias flexíveis e instáveis, através dos processos complexos de categorização.

A ideia de a referenciação ser intersubjetiva é corroborada, ainda, por Alves Filho (2010, p. 213), ao defender uma concepção dialógica de referenciação. Segundo ele (op. cit., grifos do autor), “[...] os indivíduos não referem sozinhos, porque fabricam os referentes segundo "óculos sociais”, para usar aqui expressão de Blikstein (1990), mesmo quando dão a entender que o fazem de modo individual.". Ou seja, embora o processo de referenciação seja situado/contingenciado (cf. MARCUSCHI, 2007a, p. 19), no sentido de ser realizado em uma atividade concreta de comunicação, ele envolve elementos de uma cognição social (onde entraria o papel da experiência e da cultura).

Por fim, Koch (2005, p. 33) adverte que os objetos de discurso devem ser entendidos como entidades dinâmicas do discurso que, uma vez neste inseridos, segundo a autora (op. cit.), "podem ser modificados, desativados, reativados, transformados, recategorizados, construindo-se ou reconstruindo-se".

Enfim, seguindo o exposto, delimitado principalmente por Mondada e Dubois (2003), enfatizamos a perspectiva sociocognitiva, discursiva e interacionista, para a qual os processos de referenciação são considerados como construção de objetos de discurso e de negociação de modelos de mundo.

\section{Progressão textual e constituição de cadeias referenciais}

Em nossa atividade discursiva de fala e escrita, podemos introduzir, ativar, desativar e reativar objetos de discurso, operações que envolvem aspectos cognitivos do processamento textual. Segundo explicam Koch e Elias (2008, p. 127), tais atividades correspondem à:

a) Introdução/construção: diz respeito à introdução no texto de um objeto de discurso ainda não mencionado. Dessa forma, põe-se um referente em foco, que fica saliente no modelo textual.

b) Retomada/manutenção: quando um objeto de discurso "presente" no texto é reativado por meio de uma forma referencial, de modo que permaneça em foco. ${ }^{3}$

\footnotetext{
${ }^{3}$ Cf. em Cavalcante (2011, p. 53) o que diz a autora sobre duas perspectivas de abordagem dos objetos de discurso em um texto. De acordo com a tese defendida pela autora, entendemos que um objeto de discurso
} 
c) Desfocalização: é a retirada do foco antes localizado em um objeto de discurso, motivada pelo surgimento de um novo objeto de discurso que assume a posição focal. Pode ser apenas momentânea, visto que o objeto de discurso desfocalizado (posto em stand by) pode voltar a foco. ${ }^{4}$

Dessa forma, no processo de compreensão textual, o conhecimento pode ser constantemente atualizado e colaborar na (re)construção do sentido proposto pelo interlocutor. Também, como diz Koch (2006, p. 59), a progressão textual/referencial mobiliza um processamento da referência em sua relação com os elementos do cotexto e do contexto.

Então, a eficácia na comunicação depende de vários fatores, a textualidade é um deles. Assim, para se conseguir continuidade em um texto, são necessários procedimentos de retroação a objetos de discurso antes nele introduzidos e também de progressão. Ou seja, como destacamos anteriormente, além da introdução de referentes, faz-se importante a manutenção do foco desses tais referentes, de modo que possam permanecer ativados na memória do interlocutor. De modo contínuo, as informações construídas em um dado momento no texto constituir-se-ão em suporte para novas informações. Conforme explicado por Koch e Elias (2008, p. 131), “retomada é a operação responsável pela manutenção em foco, no modelo de discurso, de objetos previamente introduzidos, dando origem a cadeias referenciais ou coesivas, que são responsáveis pela progressão referencial do texto.”.

Explica Roncarati (2010) que é pela progressão referencial (da sequencialidade) que vai se desenvolver uma cadeia referencial, "a partir da introdução, preservação, continuidade, identificação e retomada de referentes textuais” (p. 89). Tal noção, já desenvolvida por Halliday e Hasan (1976) e também por Chastain (1975) e Corblin (1995), foi atualizada por Roncarati, que considera, junto com estes últimos, haver possibilidade de ativação de um referente por procedimentos não só exclusivamente linguísticos, mas também por operações cognitivo-inferenciais. Assim também Koch e Elias (2010, p. 144) compreendem o fenômeno, ao dizerem que as cadeias referenciais

pode estar presente em um texto sem que isto implique sua explicitação. Ver também em Marcuschi (2007b, p. 40) a opinião de que "referir é, em certos casos, inferir".

${ }^{4}$ Em Koch (2002, p. 83), no lugar dos termos "introdução", "retomada" e "desfocalização", encontramos, respectivamente, os termos "ativação", "reativação" e "de-ativação". 
podem ser construídas com base em elementos presentes no texto ou que podem ser ativados a partir deles.

A constituição de uma cadeia referencial é, dessa forma, resultado da manutenção ou evolução de um objeto de discurso (cf. KOCH, 2008, p. 102). Vincula-se, assim, a vários recursos gramaticais que, juntamente com recursos de ordem lexical, são mobilizados como estratégias de progressão referencial, constituindo os vetores desse processo.

Dentre os recursos mais eficazes de progressão (e, portanto, de fabricação de cadeias referenciais), figuram as expressões nominais, que se realizam com um núcleo substantivo, podendo conter determinantes e/ou modificadores. De acordo com Koch e Elias (2010, p. 149), dentre as funções que essas expressões nominais podem exercer estão as de recategorização (retomada de um referente com alteração de suas propriedades ou acréscimo de outras, nesse caso tendo seu enquadre em outra categoria), explicação e definição de termos (ocorre com retomada de um termo pelo emprego de forma sinônima, hipônima ou hiperônima), encapsulamentos (quando uma porção anterior ou posterior do texto é sumarizada por meio de uma forma nominal ou pronominal), orientação argumentativa do texto (podem sinalizar o projeto de sentido proposto, levando o leitor às conclusões pretendidas). Por tudo isso, estes elementos são importantes carreadores de informação no curso de uma cadeia referencial.

O procedimento da recategorização, a nosso ver, pode estar vinculado à constituição de uma cadeia referencial, que não deve se limitar à correferência. Cavalcante (2011) defende a tese de a recategorização poder-se somar a qualquer fenômeno anafórico ou dêitico e ainda poder comportar índices de evolução do referente.

\footnotetext{
A recategorização pode ser abordada, como vemos, não apenas sob o viés do processamento cognitivo de como os conceitos são construídos na mente humana, mas também sob o ponto de vista discursivo, ou para salientar traços de expressividade nos arranjos estilísticos de um texto, ou para ressaltar a importância da transformação dos referentes no desenvolvimento argumentativo do discurso (CAVALCANTE, 2011, p.152).
}

Assim, por meio da recategorização, pode-se proceder à manutenção de um mesmo referente no curso de uma cadeia referencial, ainda que ele se transforme ou que dele se ressalte um determinado aspecto em relação ao seu estágio anterior. 
Halliday e Hasan (1976 apud RONCARATI, 2010) empregaram o termo "cadeia coesiva" para indicar operações textuais em que um item fazia referência a outro no contexto imediatamente precedente. Os autores propuseram três tipos de cadeias coesivas (referenciais): de identidade, de similaridade e de interação.

A cadeia de identidade é formada pela sucessão de elementos individualizados, específicos, correferencialmente vinculados (Maria $\leftarrow$ Ela $\leftarrow$ A menina); a cadeia de similaridade estabelece vínculo entre elementos de natureza diferente, não correferenciais, mas relacionados a um mesmo campo semântico de sentidos (dançar pular - correr). Já a cadeia de interação promove o vínculo entre tipos de elementos próprios de cada uma das anteriores (Na festa Maria dançou. Ela pulou e correu).

Como consideram Roncarati (2010, p. 90) e Koch (2005, p. 3), a fabricação de uma cadeia referencial, que se assenta tanto em movimentos endofóricos quanto em exofóricos, constitui uma ferramenta eficaz na produção de sentido e na argumentatividade. Assim, a análise de cadeias referenciais mostra-se um produtivo recurso aliado aos estudos do texto.

Há, ainda, várias vantagens de caráter metateórico no trabalho com cadeias referenciais, como assinala Roncarati (2010, p. 90). Destacamos, por exemplo, o fato de possibilitar a depreensão de pistas das quais o sujeito lança mão no processo de interpretação; de permitir uma observação mais pontual dos movimentos dinâmicos envolvidos nos processos de referenciação e de oferecer acesso à atribuição de coerência textual por meio da integração de unidades do fluxo informacional.

As vantagens que Roncarati (op. cit.) assinala incidem diretamente nos objetivos de nosso trabalho, no qual estamos preocupados em ressaltar a estabilização de certos objetos de discurso ainda instáveis no título. 


\section{Estabilização da referência e construção de sentidos}

\section{TEXTO 1}

\section{O NOVO CARDÁPIO DA CADEIA: PÃO COM OVO}

Bandido foi preso no Recreio. Ele é apontado como o '02' do tráfico no Fallet e tinha plano pra matar o secretário de Administração Penitenciária na Ponte Rio-Niterói

Um dos homens mais procurados do Rio, Luiz Claudio Gomes, 37 anos, conhecido como Pão com Ovo, foi preso por policiais da $26^{a}$ DP (Todos os Santos), na noite de sexta-feira. De acordo com a polícia, ele é o segundo homem na hierarquia do tráfico do Morro do Fallet e Fogueteiro, em Santa Teresa, e estava foragido desde que as comunidades foram ocupadas por Unidades de Polícia Pacificadoras (UPPS).

Segundo a polícia, o suspeito vinha sendo monitorado há dois meses. O Disque-Denúncia (2253-1177) chegou a oferecer recompensa de $R \$ 2$ mil por informações que levassem a polícia ao paradeiro do bandido. Luiz Claudio foi capturado quando passava pela Rua Rabino Henrique Lemsle, altura do número 211, no Recreio dos Bandeirantes. Ao ser abordado pelos agentes, o traficante não resistiu à prisão.

As investigações apontam que o traficante teria fugido para Niterói em agosto do ano passado, quando teria participado da invasão ao Morro dos Marítimos, em Niterói. Na época, a Polícia Militar fez operação para acabar com a guerra entre bandidos de facções rivais, e 12 foragidos do Fallet foram capturados.

Contra o acusado havia vários mandados de prisão por tráfico e homicídio. Em julho, o Ministério Público do Rio de Janeiro o denunciou por associação para o tráfico.

O preso também é acusado pela polícia de planejar atentado contra o secretário de Administração Penitenciária, César Rubens. O ataque seria na Ponte Rio-Niterói. O plano foi descoberto por meio de escutas telefônicas.

O acusado foi condenado a 25 anos de prisão por homicídio e cumpriu pena de 15 anos por tráfico de drogas. Ainda de acordo com as investigações, o traficante é ligado à facção criminosa Comando Vermelho e estava controlando bocas de fumo em Niterói. Fonte: $\quad\langle$ http://www.meiahora.ig.com.br/noticias/cat/plantao-depolicia_26.html>. Acesso em: 28 nov. 2015.

No título, a expressão referencial "O novo cardápio da cadeia" constitui uma referência metafórica e designa o "bandido" Pão com Ovo. Este jogo discursivo é motivado cognitivamente pela associação entre dois planos: (A) um onde se localiza o apelido Pão com Ovo, dado a partir do nome de um alimento; (B) outro do qual participa cardápio, a lista de alimentos que podem ser consumidos. 
A expressão "O novo cardápio da cadeia" produz, no plano B, o efeito de sentido da inclusão do "bandido" num espaço e numa dinâmica de relações em que passa de dominador a dominado, de forte a fraco, permeado por uma passividade, haja vista que se transforma em um objeto que pode ser devorado/co(nsu)mido. Já no plano A, produz o efeito de sentido de o homem, referenciado por "bandido", ser listado como um dos encarcerados.

No plano discursivo, por meio da ironia, o objeto de discurso "O novo cardápio da cadeia" evoca potencialmente o conjunto de todos esses sentidos, construídos pelo momento da leitura, em que, colaborativamente, ocorre a construção da referência, a "co-construção" (CAVALCANTE, 2011, p, 120), já que o leitor, em seu processo ativo, também é responsável pela construção da referência. Dada essa possibilidade de evocar tais significações, pode-se falar em instabilidade referencial e em estabilização da referência na evolução da leitura do texto, conforme o estudo de Costa (2013). Por decorrência deste ponto de vista, o título por si, como objeto também referencial, dificilmente será pleno, podendo também ser recategorizado no processo de processamento textual.

Assim, do título ao texto, em termos de cadeia referencial (RONCARATI, 2010), o percurso que o leitor pode trilhar em direção à estabilização da referência inclui as seguintes expressões:

(1) O novo cardápio da cadeia: Pão com Ovo (título) - ativação/introdução de referente

(2) Bandido (subtítulo) - recategorização por expressão nominal indefinida

(3) Ele (subtítulo) - retomada por pronominalização

(4) Um dos homens mais procurados do Rio (1.1) - recategorização por expressão nominal indefinida

(5) Luiz Cláudio Gomes (1.1) - retomada por aposto explicativo, forma referencial ampliada (em oposição à Luiz Cláudio, forma reduzida)

(6) Pão com ovo (1.2) - retomada parcial do referente (1) - O novo cardápio da cadeia: Pão com Ovo

(7) ele (1.3) - retomada por pronominalização

(8) (Ø) estava foragido (1.4) - retomada por elipse

(9) o suspeito (1.6) - recategorização por expressão nominal definida 
(10) (d)o bandido (1.8) - recategorização por expressão nominal definida

(11) Luiz Cláudio (1.8) - retomada por forma referencial reduzida de Luiz

\section{Cláudio Gomes}

(12) o traficante (1.10) - recategorização por expressão nominal definida

(13) o traficante (1.11) - retomada por forma idêntica

(14) (Ø)teria participado (1.12) - retomada por elipse

(15) o acusado (1.15) - recategorização por expressão nominal definida

(16) o preso (1.18) - recategorização por expressão nominal definida

(17) O acusado (1.21) - retomada por forma idêntica (1.15)

(18) o traficante (1.22) - retomada por forma idêntica (1. 10 e 11)

(19) (Ø) estava (1.23) - retomada por elipse

Nesse percurso, pode-se de pronto notar ser dinâmica a trajetória do objeto de discurso introduzido no título, mantido em foco por toda a extensão do corpo do texto, no qual sofre diversos acréscimos relacionados à evolução tópica e informacional na sua cadeia referencial (cf. Koch, 2005, p. 33, em que a autora destaca tal dinamicidade). Resolve-se, por exemplo, a instabilidade referencial instaurada no título, chegando-se à conclusão de que se trata de um "bandido", "um dos homens mais procurados do Rio", "traficante", que foi "acusado" e "preso".

A análise da cadeia referencial mostra que a estratégia de referenciação por recategorização - (2), (4), (9), (10), (12), (15), (16) - foi o procedimento mais produtivo no acréscimo de informações ao referente ativado no título. Por meio dela, o jornal opera a progressão do fluxo informacional da notícia nesse eixo temático instável no momento da ativação do referente "Pão com Ovo".

Nas retomadas por formas referenciais não recategorizantes - (5) e (11) -, também há acréscimo informacional, entretanto, isto é realizado secundariamente. Note-se que antes são feitas várias recategorizações até que seja apresentado o aposto explicativo em (5), então o leitor é apresentado primeiro à designação "bandido", primeira pista textual para a reformulação em curso.

Já as retomadas por pronominalização - (3) e (7) - e as por elipse - (8), (14) e (19) - não são responsáveis por tal progressão tópica, mantendo a informação anterior em seu mesmo estágio. A esse respeito cabe conferir a seguinte consideração de Neves (2007, p. 40): 
Quando uma oração se constrói com o chamado sujeito expresso, isso tem razões discursivo-textuais [...] nesse ponto do enunciado, um sintagma nominal se faz necessário para operar uma descrição, imprescindível, por exemplo, à configuração de uma entidade como elemento 'novo' no fluir da informação, o que não se obtém com $\varnothing$ ('sujeito oculto') e nem mesmo com ele ou ela (sujeito expresso por pronome).

Vê-se, assim, que os elementos de uma cadeia referencial cumprem funções específicas, podem ligar-se à progressão tópica ou à sua manutenção. No caso em tela, a progressão informacional é responsável diretamente pelo que tratamos por estabilização da referência (COSTA, 2013).

Por outro lado, a estabilização desses referentes constituintes do título provoca a reconstrução do conteúdo semântico deste. Sendo uma categoria esquemática, não um simples sintagma, o título é, então, tomado como uma unidade prospectiva reformulável, recategorizável.

\section{TEXTO 2}

\section{BARBIE GANHA VIDA}

Mãe coloca seios falsos em filha de apenas 4 anos

Uma americana gerou muita polêmica nos Estados Unidos, ao colocar seios e bumbum falsos em sua filhinha de apenas quatro anos, para que a criança participasse de prova num concurso de beleza infantil. A ideia da mãe, Lindsay Jackson, era fazer a pequena Maddy Jackson parecer a cantora americana Dolly Parton. Por isso, deixou a menina com aparência de mulher adulta. No concurso, a garotinha também usou uma maquiagem pesada e peruca. Também vestiu um tipo de macacão bem justo ao corpo. As imagens foram exibidas em um reality show da TV NBC. Lá, eles mostram o dia a dia de crianças que participam de competições de beleza.

Em entrevista à apresentadora do programa, Lindsay disse que isso é normal para ela e sua filha e que não vê exagero algum.

"Para algumas pessoas, é um exagero, mas para nós isso acontece... Quando ela usa os seios e o bumbum falsos, ganha um bônus", afirmou.

Mas nem todos concordam com Lindsay Jackson. Até mesmo o estilista da menina, Michael Booth, considera os enchimentos um exagero.

"Eu não sou um grande fã do equipamento nos seios dela. Ela é muito jovem, mas espero que os juízes encarem isso como de bom gosto", disse. 
Alguns grupos chegaram a lançar protestos no Facebook contra as competições, ganhando cada dia mais adeptos.

Fonte: $\quad<$ http://www.meiahora.ig.com.br/noticias/barbie-ganhavida_3892.html $>$ Acesso em: 28 nov. 2015.

De acordo com os pressupostos adotados neste trabalho, uma atividade de referenciação ocorre no desenrolar do texto, de modo que um referente não implica a coisa extralinguística, por isso, em nossa acepção, equivale ao termo objeto de discurso, que designa o conhecimento atualizado pela junção de forma linguística, conteúdo e prática sociocultural (BLIKSTEIN, 2003).

O nome Barbie, no título, corresponde a uma primeira categorização do referente que, mais adiante, será recategorizado e se desenvolverá, explicitando seu sentido no corpo do texto. Barbie é uma opção de representação de um estado de coisas posta no discurso de acordo com o sentido pretendido pelo enunciador. Trata-se, assim, da (re)construção da realidade (BLIKSTEIN, 2003; KOCH; ELIAS, 2008) e, sobretudo, da construção da realidade criada no texto. Quer dizer: uma menina de quatro anos, com maquiagem pesada, seios e bumbum artificiais, roupa colada e peruca foi, conforme o conhecimento enciclopédico ou de mundo do enunciador, designada como tal.

Esse conhecimento é, em tese, mutuamente compartilhado entre os membros de um grupo e, no processo de interação em questão, um conteúdo que fosse julgado pelo enunciador como inacessível ao interlocutor seria estrategicamente desprezado, o que evidencia a intencionalidade daquela expressão linguística.

O subtítulo desse texto, Mãe gerou polêmica ao travestir criança de adulta, é contemplado no título em parte por uma relação metafórica: por um lado, o fato de Barbie ser a mais famosa representação de bonecas que fogem ao estereótipo de bonecas-bebê ou similares, recriando o perfil de uma adolescente ou jovem mulher e, por outro, Maddy Jackson ser conceptualizada como tal, recebendo as características de Barbie.

No corpo do texto, o objeto de discurso é retomado, de modo a ser mantido em foco em todo o seu curso, numa cadeia referencial em que seu sentido vai sendo reconstruído, ao mesmo tempo em que o título vai sendo, ele mesmo, recategorizado:

(1) Barbie (título) - ativação do referente;

(2) (em) filha de apenas 4 anos (subtítulo) - retomada por meio de recategorização; 
(3) sua filhinha de apenas quatro anos (1.2) - retomada por meio de recategorização;

(4) a criança (1.2/3) - retomada por meio de expressão nominal definida, designação hiperonímica;

(5) a pequena Maddy Jackson (1.4) - retomada por meio de expressão nominal definida recategorizadora, designação hiponímica em relação à criança;

(6) a menina (1.5) - retomada por meio de expressão nominal definida, designação hiperonímica em relação à menina;

(7) a garotinha (1.7) - retomada por meio de expressão nominal definida;

(8) (Ø) vestiu (1.8) - retomada por elipse;

(9) sua filha (1.12) - retomada por expressão nominal definida;

(10) $(\varnothing)(1.14)$ - retomada por pronominalização;

(11) (Ø) ganha (1.14) - retomada por elipse;

(12) d a menina (1.15/16) - retomada por expressão nominal definida;

(13) dela (1.17) - retomada por pronominalização;

(14) Ela (1.17) - retomada por pronominalização.

Nesse desenvolvimento, em face das diversas transformações que o objeto de discurso (1) Barbie sofre, testemunha-se o seu processo de estabilização e a orientação argumentativa a ele impressa. Note-se que, em oposição à caracterização sexual exacerbada projetada na menina e consubstanciada pela expressão nominal Barbie, opõem-se, em vários momentos do texto, objetos de discurso que realçam a inocência da criança, como em (2), (3) e (5), por exemplo.

Ainda, a categorização Barbie afasta-se de uma maneira sóbria e impessoal de dizer, constituindo pistas da subjetividade do enunciador e de sua visão de mundo. Para nós, nesse sentido, evidenciam-se a apreensão e a transformação do fato em notícia segundo o prisma particular do jornalista.

Também se pode contrapor toda a cadeia referencial fabricada no corpo do texto à introdução do referente no título. Nesse procedimento, poderíamos atribuir ao título a tentativa pelo autor de imputar a sua crítica ao caso noticiado, com certo tom de informalidade e (talvez) humor, o que não se pode observar nas diversas retomadas textuais, mais formais e voltadas para o apelo dramático. 
Veja-se, então, que se podem destacar, na evolução tópica, certos objetos do discurso que recategorizam mais nitidamente a ativação feita no título. Dessa forma, há entre (2) (em) filha de apenas 4 anos e (3) sua filhinha de apenas quatro anos, uma diferença entre seus núcleos. Além de ambas enquadrarem o referente expresso por (1) Barbie em outra categoria, o que em si já configura um desenrolar da informação introduzida no título, a recategorização feita em (3) apresenta o referente redimensionado afetivamente (filha $\rightarrow$ filhinha). Na mesma direção de construção de sentidos, aponta-se a ocorrência (5) a pequena Maddy Jackson, na qual o adjetivo pequena, diferente do que se poderia objetar, não caracteriza, mas sim qualifica seu núcleo Maddy Jackson, conferindo-lhe o acento crítico intencionado.

Em suma, destaque-se que a cadeia referencial fabricada para (1) Barbie executa simultaneamente dois movimentos na construção de sentidos: no primeiro, vinculado ao fluxo informacional do texto, o jornal estabiliza a referência ativada no título e faz cumprir a finalidade de informar do gênero notícia; no segundo, associado à argumentação que perpassaria o texto, imprime-se ao conteúdo um tom de crítica, permitido pela dramaticidade que conduz as recategorizações apontadas. Além disso, note-se que a cadeia referencial percorre uma trajetória do (+) informal e (+) metafórico/instável ao (+) formal e (+) referencial/estável.

\section{Conclusão}

Ao observarmos o emprego de algumas expressões referenciais no título de notícias do jornal Meia Hora, pudemos verificar que elas estão associadas à construção de sentidos desviantes. Se, de um lado, as expressões referenciais oferecem indícios da imagem do leitor formulada pelo jornal(ista), via uma abordagem predominantemente informal, também, por outro lado, denunciam uma visão subjetiva de como um fato é construído pela instância de produção.

A análise das expressões referenciais em títulos de notícias desse jornal demonstrou que são um fecundo espaço de observação de como, a partir delas, constróise discursivamente um perfil idealizado de leitor. Parte dessa projeção sobre o leitor pode ser medida ainda pela referida apreciação subjetiva, muitas vezes avaliativa, da instância 
de produção na concepção do fato e como espera que o leitor o receba, antecipando-se a ele.

A análise das cadeias referenciais nas notícias deste corpus demonstrou que a trajetória de algumas expressões referenciais no título segue o percurso do $(+)$ informal $e(+)$ metafórico/instável ao $(+)$ formal $e(+)$ referencial/estável, ou seja, alguns objetos de discurso-chave na construção do título sofrem alterações no seu registro de modo que um título informal seja seguido, na sequência, por um subtítulo em geral mais formal. A partir disso, inferimos que essa especificidade faz parte de uma estratégia de aproximação entre jornal e leitor.

A nosso ver, a razão de tais expressões referenciais informais do título serem retomadas por expressões mais formais está associada também ao que consideramos por “estabilização da referência”, visto que o duplo sentido/ambiguidade por nós ressaltado teria como ponto de partida justamente a possibilidade de mais de uma interpretação delas decorrente.

A estabilização da referência e do conteúdo efetivamente noticiado é uma necessidade da qual o jornal não poderia prescindir, uma vez que ele possui objetivos comerciais e compromissos profissionais que o definem como tal, o que exige a "veracidade" da notícia (em oposição à sua falsidade), pois nisto também repousa a credibilidade do jornal. Daí, na construção do texto, o jornalista ter de operar com expressões mais estáveis do núcleo temático da notícia ou resolver a sua instabilidade antes do seu final. Isso explica o uso, no corpo do texto, de linguagem mais formal bem como a presença de uma cadeia referencial alinhada ao conteúdo efetivamente noticiado.

Por fim, para além das expressões referenciais, até mesmo as categorias estruturais do gênero textual estudado (a notícia) são passíveis de serem consideradas pela perspectiva da referenciação. Assim, sendo elementos constituintes do ato de comunicação, também os títulos, seja no jornal Meia Hora ou em qualquer outro, não podem ter seu sentido dado a priori. Dessa forma, estendemos os conceitos ligados à dinamicidade das expressões referenciais, sejam a "construção" e "reconstrução" no fio do discurso, a tal categoria esquemática (o título). Finalmente, registramos que, de acordo com nossa abordagem, os estudos sobre a atividade de referenciação podem incluir categorias esquemáticas várias de gêneros textuais diversos como unidades de estudo, o 
que implica considerar, para além do nível microtextual, o macrotextual como espaço de observação da construção de sentidos.

COSTA, Wagner Alexandre dos Santos; MENEZES, Vanda Maria Cardozo de. Referential chains and sense production in popular journalism. Revista do Gel, São Paulo, v. 13, n. 3, p. 241-259, 2016.

\begin{abstract}
The successive retaking of a linguistic item in a text promotes a referential/textual chain. The study of the linguistic-discursive procedures of these chains can be a valuable tool for uncovering intentionality and meaning production. In news, aspects like informational evolution, drama/humor construction and the way the journal interprets the content are important cues for meaning production and comprehension. By the light of Textual Linguistics, we developed a qualitative analysis on the referential progression of certain referentially unstable lexical items present in titles of popular news, all extracted from Meia Hora, a popular Rio newspaper, in accordance with the perspectives of Mondada (2005), Koch and Elias (2008), Marchuschi (2004), Choi (2011) and Roncarati (2010). As a methodological procedure, we isolated the referential chains from the corpus and established the relationships among its components, trying to understand the stabilization process of the item/source, present in the title. The results show that the subtitle is the first space to build hypotheses tuned to the overall content of the text. It was also noted that the referential chain amounts to a trajectory of $(+)$ informal and $(+)$ metaphorical/unstable to $(+)$ formal and $(+)$ referential/stable. In addition to this, we consider the category title - particularly in the journalism sphere - as a dynamic and changeable referential unit that can be recategorized as discourse flows.
\end{abstract}

Keywords: Referential chains. Stabilization. Popular journalism.

Submetido em: 13/03/2016.

Aceito em: 03/06/2016.

\title{
Referências
}

ALVES FILHO, F. "Sua casinha é meu palácio": por uma concepção dialógica de referenciação. Linguagem em (Dis)curso. Palhoça, v. 10, n. 1, p. 207-226, jan./abr. 2010.

BENVENISTE, É. Problemas de linguística geral II. 2. ed. Campinas: Pontes, 2006.

O aparelho formal da enunciação. In. BENVENISTE, É. Problemas de linguística geral II. 2. ed. Campinas: Pontes, 2006, p. 81-90.

BLIKSTEIN, I. Kaspar Hauser ou a Fabricação da Realidade. 9. ed. São Paulo: Cultrix, 2003. 
CAVALCANTE, M. Referenciação: sobre coisas ditas e não ditas. Fortaleza: Edições UFC, 2011.

CHASTAIN, C. Reference and Context. In: GUNDERSONK, K. Language, Mind and Knowledge. Minneapolis: University of Minnesota Press, 1975.

CORBLIN, F. Les forms de reprise dans le discours - anaphores et chaînes de reference. Renner: Presses de I’Université de Rennes, 1995.

COSTA, W. A. dos S. Do título ao texto. Do texto ao título: o processo de estabilização da referência em notícias do jornal Meia Hora. 2013. 212 f. Tese (Doutorado em Estudos da Linguagem) - Instituto de Letras, Universidade Federal Fluminense, Niterói, 2013.

HALLIDAY, M. A. K.; HASAN, R. Cohesion in English. Londres: Longman, 1976.

KOCH, I. Desvendando os segredos do texto. 2. ed. São Paulo: Cortez, 2002.

Referenciação e orientação argumentativa. In: KOCH, I. V.; MORATO, E. M.; BENTES, A. C. (Orgs.). Referenciação e discurso. São Paulo: Contexto, 2005.

Introdução à Linguística Textual. São Paulo: Martins Fontes, 2006.

Como se constroem e reconstroem os objetos-de-discurso. Investigações. v. 21, p. 2008. 99-114, Disponível em: 〈http://www.ufpe.br/pgletras/Investigacoes/Volumes/Vol.21.2/Ingedore_Koch.pdf >. Acesso em: 25 jan. 2010.

KOCH, I.; ELIAS, V. M. Ler e compreender: os sentidos do texto. 2. ed. São Paulo: Contexto, 2008. 2010.

Ler e Escrever: estratégias de produção textual. 2. ed. São Paulo: Contexto,

MARCUSCHI, L. A. O léxico: lista, rede ou cognição social? In: NEGRI, L.; FOLTRAN, M.; OLIVEIRA, R. (Orgs). Sentido e Significação: em torno da obra de Rodolfo Ilari. São Paulo: Contexto, 2004.

Coerência e cognição contingenciada. In.: MARCUSHI, L. A. Cognição, linguagem e práticas interacionais. Rio de Janeiro: Lucerna, 2007a. p. 13-30.

Cognição, explicitude e autonomia no uso da língua. In.: Cognição, linguagem e práticas interacionais. Rio de Janeiro: Lucerna, 2007b. p. 31-61.

MENEZES, V. M. C. Referenciação, uso do léxico e letramento. Revista Interseções, Jundiaí, v. 1, p. 81-92, 2016. 
MONDADA, L. Referência como trabalho interativo: a construção da visibilidade do detalhe anatômico durante uma operação cirúrgica. In: KOCH, I. V.; MORATO, E. M.; BENTES, A. C. (Orgs.). Referenciação e discurso. São Paulo: Contexto, 2005.

MONDADA, L.; DUBOIS, D. Construção dos objetos de discurso e categorização: Uma abordagem dos processos de referenciação [1995]. In: CAVALCANTE, M. M.; RODRIGUES, B. B.; CIULlA, A. (Orgs). Referenciação. São Paulo: Contexto, 2003.

NEVES, M. H. de M. Texto e gramática. São Paulo: Contexto, 2007.

RONCARATI, C. As cadeias do texto: construindo sentidos. São Paulo: Parábola, 2010. 